\title{
Bourdieu e Goffman: Um ensaio sobre os pontos comuns e as fissuras que unem e separam ambos os autores a partir da perspectiva do primeiro
}

\section{Bourdieu and Goffman: an essay on the common points and differences between both authors according to Bourdieu's perspective}

\section{Felipe Tavares Paes Lopes *}

Doutorando em Psicologia Social pela Universidade de São Paulo - USP, São Paulo, SP, Brasil

\begin{abstract}
Resumo
Neste trabalho, tenho como principal objetivo discutir dois modelos teóricos que buscam analisar a dimensão fenomênica do ser: a ação. Mais especificamente, proponho uma reflexão acerca dos pontos comuns e das fissuras que unem e separam a teoria da ação de Erving Goffman daquela proposta por Pierre Bourdieu. Para tanto, apoiei-me, sobretudo, nos comentários e críticas deste último ao primeiro, estruturando o trabalho em duas partes. Num primeiro momento, procurei descrever e analisar as principais críticas que os dois autores fazem ao modelo objetivista de análise da ação. Num segundo momento, procurei descrever e analisar as principais críticas que Bourdieu faz ao modelo subjetivista goffmaniano, indicando os interstícios epistemológicos, ontológicos e metodológicos que o afasta dele.
\end{abstract}

Palavras-chave: Erving Goffman, Pierre Bourdieu, Teoria da ação, Habitus, Representações do Eu.

\begin{abstract}
In this work, my main purpose is to discuss two theoretical models that analyze the phenomenical dimension of human being: the action. More specifically, I suggest a reflection on the common points and the differences which bond and separate Pierre Bourdieu's action theory and the one proposed by Erving Goffman. To achieve this purpose, I based this essay on Bourdieu's commentaries and critiques on Goffman's theory, and I divided this paper in two parts. In the fist one, $I$ described and analyzed the main criticisms both authors make about the action's analyze objectivist model. In the second part, I described and analyzed the main criticisms Bourdieu makes about Goffman's subjectivist model, pointing their epistemological, ontological and methodological differences.

Keywords: Erving Goffman, Pierre Bourdieu, Action's theory, Habitus, Presentations of self.
\end{abstract}




\section{Apresentação}

Neste trabalho, tenho como principal objetivo discutir dois modelos teóricos que buscam analisar a dimensão fenomênica do ser: a ação. Mais especificamente, proponho uma reflexão acerca dos pontos comuns e das fissuras que unem e separam a teoria da ação de Erving Goffman daquela proposta por Pierre Bourdieu. Para tanto, apoiei-me sobretudo nos comentários e críticas deste último ao primeiro. A opção por investigar esses dois modelos teóricos se justifica uma vez que ambos se destacam como poderosos instrumentos científicos, servindo de base analítica para diversas pesquisas em psicologia social e outros campos do conhecimento. Ciente da desaprovação de Bourdieu em relação ao enfrentamento puramente teórico de sua teoria com outras, é forçoso reconhecer que o presente trabalho pode muito bem ser classificado como "nãobourdieusiano". Entretanto, parece-me que esse veredicto não o desqualifica completamente. Isso porque não pretendo fazer aqui uma "teoria teórica", dispensando arrogantemente a confrontação das análises aqui realizadas com futuras investigações empíricas. Mas apenas contribuir para o debate em torno dos modelos teóricos supracitados, oferecendo novos subsídios conceituais para tais investigações.

$\mathrm{O}$ texto foi estruturado em duas partes. Na primeira, procurei descrever e analisar as principais críticas que Goffman e Bourdieu fazem ao modelo objetivista de análise da ação, destacando as vantagens potenciais de suas teorias em relação a esse modelo. Na segunda, procurei descrever e analisar as principais críticas que Bourdieu faz ao modelo subjetivista goffmaniano, indicando os interstícios epistemológicos, ontológicos e metodológicos que os afasta dele.

\section{As críticas de Bourdieu e Goffman ao modelo objetivista de análise da ação}

Sem sombra de dúvida, o objetivismo se faz presente, de alguma forma, em toda a história do pensamento ocidental. No entanto, é no século XIX que vai ganhar corpo, possuindo "sua expressão teórica, na sociologia clássica, na figura de Durkheim"(MARTINS, 1987, p.37). I nvestindo contra a fé iluminista no ser humano auto-suficiente e racional, a obra durkheiminiana desenvolve uma teoria preocupada fundamentalmente em explicar as práticas individuais a partir das relações objetivas que as estruturam - recusando, portanto, quaisquer explicações psicologizantes dessas práticas. É por isso que, de acordo com Bourdieu (apud MARTINS, 1987), "uma das questões básicas que o objetivismo irá introduzir na explicação sociológica é das condições particulares, que tornam possível o 
mundo social"(p.37). Hoje, segundo Burrel e Morgan (1979), essa perspectiva é representada essencialmente por dois paradigmas: o funcionalismo e o estruturalismo radical. Ambos são criticados por Goffman e Bourdieu, uma vez que, de acordo com eles, reificam o mundo social e, consequentemente, a ação de seus agentes.

\subsection{A crítica à reificação do mundo social}

"A sociedade é Deus", as famosas palavras de Durkheim - repetidas e problematizadas anos mais tarde por Bourdieu no seu curso inaugural no Collège de France - parecem sintetizar muito bem a sociologia do primeiro e suas dificuldades decorrentes. Mais concretamente, sua convicção no poder absoluto das forças sociais sobre os agentes sociais, também explicitada na sua concepção de fato social, definida por ele (DURKHEIM,1978, p.92) como toda a maneira de fazer, fixada ou não, suscetível sobre o indivíduo uma coação exterior, ou ainda, que é geral no conjunto de uma dada sociedade tendo ao mesmo tempo, uma existência própria, independente das suas manifestações individuais.

Ao formular a concepção de fato social, Durkheim escapa da velha fé iluminista, além de fortalecer a importância do levantamento de material empírico para o estudo da sociedade (diga-se de passagem, idéia compartilhada tanto por Bourdieu quanto por Goffman). Entretanto, de acordo com seus críticos, essa concepção transforma a realidade social numa entidade autônoma - independente dos agentes que a constituem.

De acordo com Martins (1987, p. 38), na concepção de Bourdieu, o objetivismo ao privilegiar a lógica da estrutura, apreendida de maneira sincrônica, sobre a história individual ou coletiva [...], condena-se a apenas a registrar a produção de regularidades da vida social, ou a reificar abstrações, o que consiste em tratar os objetos construídos pela ciência, como por exemplo "a cultura", "as classes sociais", "os modos de produção" ou outras categorias, como realidades autônomas, dotadas de uma eficácia social capazes de agir por si próprias, substituindo dessa forma os agentes sociais.

Para escapar desse equívoco analítico, Goffman, seguindo Weber, opta por se assentar numa perspectiva da compreensão. Isto é, por resgatar o agente para as análises do mundo social. Assim, se na obra de Durkheim ele é recalcado, na de Goffman, trata-se do ponto de partida para a compreensão das interações sociais e das representações ${ }^{\underline{1}}$ que nelas são forjadas. Com isso, interpreta os sentidos das ações humanas como sendo estabelecidos subjetivamente - atribuídos pelo agente social que comunica e que é comunicado. Desta forma, de acordo com Ortiz (1983, p.12), ao comparar as obras de Goffman e Bourdieu, o primeiro, em contrapartida à analise objetivista, compreende o mundo social como uma 
rede de intersubjetividade, enquanto resultados de ações dirigidas para o outro e que adquirem significado em que o outro compartilha [conosco] o mesmo mundo social no qual tais ações se desenrolam.

Ao assumir esta perspectiva, Goffman afasta-se, então, do objetivismo. Bourdieu, por sua vez, não apenas reintroduz o agente social na sua análise, como faz Goffman, como também reencontra sua mediação com a sociedade. Para tanto, desenvolve dois conceitos interdependentes: o primeiro diz respeito ao princípio orientador das percepções e práticas dos agentes sociais; o segundo, ao espaço social onde, num mundo onde a divisão social do trabalho é altamente complexificada, como as sociedades industriais modernas, esse princípio é adquirido e interiorizado.

Assim, visando à superação da dicotomia tradicional de visão da sociedade, estabelecida pela concorrência entre a tradição de inspiração marxista - que considera que "a sociedade está dividida em classes econômicas antagônicas a partir de um critério econômico" (BONNEWITZ, 2005 , p. 51) - e a de inspiração weberiana, que "analisa a sociedade em termos de estratos constituídos a partir de três princípios de classificação: poder, prestígio e riqueza", (BONNEWITZ, 2005, p. 51), Bourdieu desenvolve sua concepção de campo social. Esta concepção não apenas se recusa a se inscrever nessa dicotomia tradicional, visando à sua superação e síntese, mas possui um alvo bastante específico: a concepção de aparelho e, mais especificamente, a de Aparelhos Ideológicos de Estado (AlE), de Althusser.

Segundo este último (1974, p. 42), sua intenção ao elaborar a concepção de AIE objetivava, sobretudo, fazer avançar a "teoria marxista do Estado". Nas suas palavras, para se avançar na teoria do Estado, é indispensável ter em conta, não só a distinção entre poder de Estado e aparelho de Estado, mas também outra realidade que se situa manifestamente ao lado do aparelho (repressivo) de Estado, mas não se confunde com ele.

Esta outra realidade são justamente os AIE, definidos por Althusser (1974, p.43) como um certo número de realidades que se apresentam ao observador imediato sob a forma de instituições distintas e especializadas [a Igreja, o sistema escolar, o familiar, o jurídico, o político, o sindical, o cultural e os meios de comunicação de massa etc.] e que funcionam mais pela ideologia do que pela repressão.

Certamente, a noção de AIE tem o mérito de iluminar uma questão que, até então, a "teoria marxista de Estado" ainda não havia, sob a forma de uma sistematização teórica, avançado devidamente: a de como as sociedades capitalistas contemporâneas - e consequentemente as necessidades e interesses das classes e grupos dominantes - são, não apenas organizadas pelo estado e asseguradas pelo seu modo específico de produção, mas também legitimadas pelo simbólico. Para Althusser, são, em grande medida, os valores e crenças difundidos pelos AIE que 
mantém a ordem social nas sociedades baseadas em divisões de classe. Apesar dos avanços evidentemente trazidos por sua teoria, Bourdieu não deixa de considerá-la seriamente deficiente.

A razão disso decorre dos AIE serem, da sua perspectiva (1983), instituições basicamente refratárias às demandas de outras classes ou grupos de interesses que não os dominantes, como se todos os seus aspectos e atividades pudessem, em última instância, ser analisados apenas em termos de exploração de classe. Ainda, como se a ideologia difundida por esses aparelhos tivesse um enorme poder de "amalgamento", de cimentação das relações sociais, e, consequentemente, conseguisse, como observa Thompson (1995), anular, em grande medida, o desacordo, o ceticismo, o cinismo, a contestação e o conflito. Nesse sentido, as classes subalternas não subverteriam a ordem social, entre outras coisas, porque compartilhariam de idéias consensuais e convergentes difundidas pelos AIE.

Assim, no limite, para Bourdieu, os AIE constituem uma parcela do estado que funciona como um mecanismo onde e por meio do qual os valores e crenças dominantes se materializam, unindo agentes de todos os extratos numa mesma ideologia, ou seja, funciona como mecanismos que garantem, de cima para baixo, a coesão e a reprodução da ordem social. Por esta razão, de acordo com ele (1983), os AlE funcionam como algo monolítico, "uma máquina infernal, programada para realizar certos fins" (p.106); e não como "sociedades na sociedade", "microcosmos dentro do macro-cosmos". Melhor dizendo, como espaços que operam como campos sociais, ou seja, como universos dinâmicos e relativamente autônomo, com certo grau de estruturação interna que lhe confere alguma independência em relação a outros universos sociais - definida em função da autonomia de seus troféus, instâncias de consagração e legitimação.

Propor uma abordagem em termos de campos sociais é, de acordo com o sociólogo francês, não apenas iluminar essas características típicas desses contextos sociais, mas, também, apontar para o fato de que dominantes e dominados não podem ser, nesses contextos específicos, definidos isoladamente, mas apenas uns em relação aos outros, numa luta constante pelos troféus específicos do campo. Nas suas palavras (BORDIEU, 1983, p. 106), nos campos sociais, agentes e instituições estão em luta, com forças diferentes e segundo regras constitutivas deste espaço de jogo, para se apropriar dos lucros específicos que estão em jogo neste jogo. Os que dominam o campo possuem os meios de fazê-lo funcionar em seu benefício; mas devem contar com a resistência dos dominados.

Sendo assim, podemos dizer que os campos sociais não possuem uma estrutura fixa, mas sim relativamente volúvel, estando em movimento constante. Com isso, sua dinâmica assemelha-se a de um jogo sem fim, contando com um eterno avançar e recuar dos grupos em disputa. Às 
vezes, com o grupo dominado aderindo à "heterodoxia"; outras vezes, mais frequentemente, à "ortodoxia" - quando, estrategicamente, aliam-se ao grupo dominante visando à sua sucessão. Diante dessa dinâmica específica, de acordo com Bourdieu (1983, p. 106), o funcionamento desses espaços só poderá assemelhar-se ao de um aparelho em situações muito particulares - e, ainda assim, jamais alcançadas na sua plenitude:

quando os dominantes possuem meios de anular os dominados. [Quando] estes não podem fazer mais do que sofrer a dominação; quando todos os movimentos são de cima para baixo e os efeitos de dominação são tais que a luta e dialética constitutiva do campo cessam.

Com efeito, da perspectiva do autor, as instituições totais de que trata Goffman - aquelas "simbolizadas pela barreira à relação social com o mundo externo e por proibições à saída que muitas vezes estão incluídas no esquema físico" (GOFFMAN, 1999, p.16), - objetivam justamente o estabelecimento desse tipo de situação, isto é, anular todo conflito que ocorre em seu interior e, com isso, funcionar, de certo modo, como aparelhos. Afinal, um aparelho, da perspectiva de Bourdieu (1997, p.193), funciona sempre de cima para baixo, ou seja, fazendo desaparecer "toda a luta e toda a resistência à dominação".

Além disso, um aparelho - mais especificamente um AIE - funciona como um mecanismo que objetiva impor aos agentes sociais uma visão única e unificadora de mundo. Do mesmo modo, as instituições totais, ao isolarem os agentes sociais do mundo externo, buscam provocar uma "desfiguração pessoal", que consiste não apenas numa mutilação direta e permanente do corpo, como ocorre muitas vezes nos manicômios, prisões e conventos, mas como, observa o próprio Goffman (1999, p. 31), romper a fronteira que existe entre o agente social e o ambiente, profanando, nas suas palavras, "as encarnações do eu".

Assim, de acordo com ele, os internos das instituições totais, em virtude do seu isolamento e "esmagados" pelo "peso" que essas instituições exercem sobre eles, deixam de interpretar os papéis sociais que interpretavam outrora, antes do internamento. Consequentemente, são desnudados de praticamente tudo o que constituía sua identidade social anterior, tendo seus eus sistematicamente mutilados e mortificados. Porém, não de forma suficiente para neutralizar por completa sua resistência às imposições dessas instituições. De acordo com Bourdieu, em "Manicômios, Prisões e Conventos", Goffman mostra justamente como os internos desenvolvem estratégias originais de resistência, ainda que pouco visíveis a um primeiro olhar (BOURDIEU; WACQUANT, 1992).

Por esta razão, podemos dizer, inclusive, que a denominação "instituição total" é, de certo modo, inadequada. Afinal, como acabamos de observar, o próprio Bourdieu ressalva que a institucionalização das práticas e idéias propagadas pelos agentes dominantes dessas instituições, pelos seus 
dirigentes, nunca é "total", isto é, completa e radicalmente horizontal, mas é sempre parcial, confrontada pelos agentes dominados.

Caso contrário, se ela fosse de fato "total", certamente seria o fim da história desses espaços sociais. Afinal, tratar-se-ia de um lugar inerte e engessado, onde não haveria lugar para a transformação, isto é, para o desenvolvimento de metamorfoses sociais e individuais. Tratar-se-ia, portanto, de um lugar onde os internos não passariam de joguetes. Assim, podemos dizer, em alguma medida, que é porque considera a possibilidade de resistência que, ao elaborar a concepção de instituição total, Goffman não recai no objetivismo. Este que, por sua vez, ao aparelhar os espaços sociais que analisa, retira da ação de seus agentes seu caráter crítico e potencialmente ativo.

\subsection{A critica à reificação dos agentes sociais}

Se o objetivismo reifica o mundo social, por conseguinte, não deixa de fazê-lo com os agentes sociais. Afinal, joga tanta luz na sua condição estruturada, que ofusca a estruturante, fazendo deles meros epifenômenos da sociedade. Nas palavras de Ortiz (1983), apresentandoos como reprodutores "de algo que se encontra objetivamente programado e que lhe é exterior. [Por isso], dentro dessa perspectiva, o ator social se apresenta necessariamente como simples executor da abstração como a 'cultura', a 'estrutura', a 'língua'” (p.11). Ou seja, como uma espécie de cabide dessas categorias, "simples receptáculo de normas e valores impostos de fora para dentro, através do condicionamento" (BONNEWITZ, 2005, p. 81). Ou ainda, para Althusser e seu estruturalismo, como um apparatchik, que deve tudo ao aparelho, um aparelho tornado ser humano, feito de vísceras e sangue, pronto, nas meditações pascalianas de Bourdieu (1997, p. 194), a dar tudo a um aparelho que the deu tudo: podem-se-Ihe confiar sem temor as maiores responsabilidades uma vez que ele nada pode fazer progredir seus interesses sem atender ao mesmo tempo às expectativas e aos interesses do aparelho; como o oblato, está predisposto a defender a instituição, com a mais firme convicção, contra as ameaças suscitadas pelos desvios heréticos dos detentores de um capital adquirido fora da instituição, que se sentem autorizados tendentes a tomar distância em relação às crenças e hierarquias internas.

Para além dessa perspectiva e de qualquer objetivismo reificador, Bourdieu desenvolve a concepção de habitus. Com a apropriação e problematização desse conceito de origem aristotélica - posteriormente retomado por Merleau Ponty na sua "Fenomenologia da Percepção" - o sociólogo francês contrapõe-se ao objetivismo. Para ele, grande parte das ações humanas, seguindo o próprio objetivismo que critica, não é 
resultada de uma espontaneidade criadora, tampouco de um cálculo consciente ou, melhor ainda, de uma estratégia racional que visaria, a todo o momento, à maximização de um lucro (homo economicus). Mas sim de um saber prático que os agentes sociais acumulam ao longo de suas trajetórias e que os permitem ter uma relação com o futuro de protenção, e não de projeto $²$. Com um "a ser vivido" imediatamente percebido - um "quase presente" - e não apenas com um futuro como um possível imaginado como tal (BOURDIEU, 1994).

A concepção de habitus pode ser compreendida, portanto, como uma aptidão dos agentes sociais para se moverem e se orientarem num determinado espaço social, segundo a lógica específica desse próprio espaço, sem que tenham de necessariamente recorrer ao cálculo explícito. Mais concretamente, a concepção de habitus pode ser compreendida como um sistema de disposições duradouras que os agentes adquirem por meio de suas inserções nos mais variados espaços sociais - seja ele, por exemplo, o ambiente familiar ou profissional - e que constituem uma matriz de percepção, de apreciação e de ação que se realiza em condições sociais análogas as quais essa matriz foi adquirida. Com isso, os agentes sociais tendem, nessas situações análogas de existência, a agir de forma muito semelhante ao modo como agiram anteriormente. Ainda, a se portarem, sem saber ou perceber, de modo muito similar a milhares de outros que possuem o mesmo habitus. Por esta razão, podemos dizer com Bonnewitz (2005, p.75) que, para Bourdieu, “a socialização, realizando a incorporação dos habitus de classe, produz a filiação de classe dos indivíduos, realizando ao mesmo tempo a classe enquanto grupo que compartilha o mesmo habitus". Daí, evidentemente, o habitus estar na base da reprodução da ordem social.

Entretanto, se o habitus pode ser considerado um princípio de conservação, ele, como assinala o comentador supracitado, "também pode tornar-se um mecanismo de invenção e, consequentemente, de mudança" (BONNEWITZ, 2005, p. 75). Afinal, uma situação nunca é exatamente igual à anterior, uma vez que o presente, ainda quando parece reproduzir o passado, é sempre, de alguma forma, inédito. Sendo assim, as condições de atualização do habitus nunca podem ser idênticas as que o produziram. Por vezes, são apenas semelhantes; por outras, nem isso. Em especial, em todos os casos em que os agentes perpetuam disposições tornadas obsoletas pelas transformações das condições objetivas (envelhecimento social), ou quando ocupam posições capazes de exigir disposições diferentes daquelas derivadas de sua condição de origem (BOURDIEU, 1997, p.196).

Daí, evidentemente, o habitus não ser necessariamente adaptado e coerente com as situações sociais em que se concretiza. Ocasionalmente, pode até ser contraditório a elas. Nestes casos, os agentes sociais acabam cometendo "gafes", fazendo ou dizendo coisas "inconvenientes". Melhor 
dizendo, nestes casos, os agentes sociais acabam sofrendo uma dupla constrição: a do próprio habitus e a do universo social em que se encontram. Constrição que, de acordo com Bourdieu (1997, p. 194), pode resultar no dilaceramento psíquico desses agentes, fazendo-os sofrer profundamente. Deste modo, segundo ele, o fato de que as respostas engendradas sem cálculo ou projeto pelo habitus surjam, com frequência, como que adaptadas, coerentes, e imediatamente inteligíveis, não deve levar a que se faça delas uma espécie de instinto infalível, capaz de produzir a todo instante respostas milagrosamente ajustadas a quaisquer condições.

Assim se a noção de apparatchik condena-se apenas a registrar a produção de regularidades da vida social, transformado os agentes sociais em máquinas coerentemente estruturadas, a noção de habitus joga luz na forma, nem sempre harmônica, como é feita a mediação entre eles e a sociedade em que vivem, isto é, na dimensão estruturada e estruturante de seu agir. Melhor dizendo, joga luz na dimensão socialmente construída de seus corpos, que incorporam "as estruturas do mundo e que [estruturam] tanto a percepção quanto a ação" (BOURDIEU, 1997, p. 194). Sendo assim, podemos compreender o habitus como sendo o próprio espaço social, com todas as suas contradições, "feito em corpo". $\mathrm{Na}$ definição do próprio Bourdieu (1972,p. 175), um sistema de disposições duráveis, estruturas estruturadas predisposta a funcionarem como estrutura estruturantes, ou seja, como princípios que geram e estruturam as práticas e as representações que podem ser objetivamente regulamentadas e reguladas sem serem o produto de obediência de regras, objetivamente adaptadas a um fim, sem que se tenha necessidade da projeção consciente deste fim ou do domínio das operações para atingi-lo, mas sendo, ao mesmo tempo, coletivamente orquestradas sem serem o produto da ação organizadora de um maestro (tradução do autor).

Se essa complexa noção se contrapõe a idéia de que o ser humano é algo mecânico, programado, o subjetivismo goffmaniano não faz diferente. Goffman faz carreira nos Estados Unidos no pós-guerra, ambiente em que o funcionalismo de Talcott Parsons, herdeiro da corrente sociológica desenvolvida por Durkheim, tem enorme prestígio. Contrapondo-se a essa corrente $^{3}$, assume uma sociologia da compreensão. Nesta, o agente social volta a ser o centro das atenções e, com isso, a sociedade passa a ser interpretada não como uma realidade exterior e superior, mas como o produto das ações humanas. Produto prenhe de sentidos contraditórios. Assim, o resultado de uma ação pode receber sentidos muito diferentes, dependendo dos valores, desejos e expectativas do agente que a percebe. Deste modo, os agentes sociais deixam a condição de senhores das consequências de seus atos ou, melhor ainda, da de meros "joguetes" do social - "esponjas" que tudo absorve indiscriminadamente. Para o 
subjetivismo goffmaniano, uma análise do mundo social tem, portanto, de resgatar "o sentido da ação humana tal como é subjetivamente concebido" (LALLEMENT, 2003a, p.265).

Por isso, Goffman principia "A representação do eu na vida cotidiana" (RE) (2003, p. 25) elucidando que sua análise parte do exame da "própria crença do indivíduo na impressão de realidade que tenta dar àqueles entre os quais se encontra". Isto é, do sentido que atribui a ela. Esse esclarecimento evidencia, sem dúvida, a importância que confere à compreensão que os agentes sociais têm da realidade social - escapando, assim, da tentação de reificá-los. De cair nos equívocos da perspectiva objetivista, mas não sem cair em outros, como nos mostra Bourdieu.

\section{As críticas de Bourdieu ao modelo subjetivista de Goffman de análise da ação}

Embora a crítica ao modelo subjetivista de análise não seja recente, tenha percorrido toda a história do pensamento ocidental, fazendo parte da obra de inúmeros pensadores, podemos dizer que, na modernidade, é a partir do trabalho de Durkheim que ela adquire maior consistência (BARROS FILHO, 2002). Seguindo essa tradição de crítica, em "Le sens pratique"(1980), Bourdieu condena impetuosamente aqueles que compartilham da perspectiva fenomenológica - por ele identificado com o subjetivismo. Para ele, a fenomenologia tem, na sociologia clássica, Weber seu grande representante, uma vez que, como observa Martins (1987, p. 36), essa corrente "toma como ponto de partida o sujeito da ação para a elaboração de uma sociologia da compreensão". Da mesma forma, da sua perspectiva, as orientações metodológicas subjetivistas contemporâneas têm, na etnometodologia, no existencialismo sartreano e nos interacionistas simbólicos, seus principais expoentes. Goffman, representante desta última, é desigualmente citado, analisado e criticado por Bourdieu em seus principais trabalhos. Dois são os pontos mais visíveis de incompatibilidade da proposta goffmaniana com a sua sociologia: o modelo de análise do mundo social e, consequentemente, o sentido dado às interações sociais. Ambos são objetos de crítica do sociólogo francês.

\subsection{A crítica à teatralização do mundo social}


Os fenômenos sociais podem ser abordados subjetivamente de muitas maneiras. Assim fizeram uma enormidade de pensadores: na filosofia, Sartre é um exemplo recente; na sociologia, Weber, um clássico. Ambos são exemplos de autores que tomam o agente social como ponto de partida para suas análises. Goffman, sem dúvida, segue essa tradição. Sua teoria da ação, embora compartilhe da idéia de que "tudo é socialmente determinado", não compreende o agente social como simples executor das exigências de um mundo social reificado. Pelo contrário, compreende-o como capaz de, numa situação social qualquer, a partir de algumas informações iniciais sobre os outros participantes da situação, identificá-los antecipadamente: sabendo o que esperar deles e o que esses devem esperar dele. Além disso, para Goffman (2003), a partir dessa identificação de origem, o agente social é capaz de manipular a impressão que deseja causar nesses outros participantes - é capaz, portanto, de conduzir a relação que começa a estabelecer, de esculpir sua identidade social.

Logo no prefácio de RE (GOFFMAN, 2003), apresenta seu modelo: o da representação teatral, que faz uso dos princípios dramatúrgicos - ator, papel, cenário, platéia etc. - e de suas diferentes técnicas teatrais para compreender o mundo social. Nele, o agente que age é interpretado fundamentalmente como um ator que desempenha um papel social e que, ao desempenhá-lo, solicita implicitamente de seus observadores que o papel representado seja levado a sério, ou seja, que acreditem que, de fato, a atividade exercida por ele tem as consequências que habitualmente se acredita ter. Melhor dizendo, que as coisas são como aparentam ser e que, portanto, ele possui os atributos que faz crer possuir. No limite, solicita que seu fenômeno seja identificado com a totalidade de seu ser. As estratégias que os agentes sociais utilizam para regular, dirigir, bem como os limites da construção desses fenômenos, constituem justamente o objeto das análises de Goffman. A opção pelo modelo dramatúrgico, posteriormente convertido num tipo especial de esquema de referência (theatrical analysis), evidencia, para alguns de seus comentadores (MALUFE, 1992; NUNES, 2005) - bem como para o autor deste trabalho, a influência da perspectiva fenomenológica na sua análise.

Mas o que é um fenômeno? Um fenômeno significa "aquilo que se mostra" (CARMO, 2004), isto é, como o mundo se apresenta a nós. Para a fenomenologia, portanto, nunca podemos apreender o mundo "nele mesmo". Isto não significa, contudo, que um fenômeno seja uma ilusão, apenas que ele sempre se apresenta para uma consciência. Desta forma, para um fenomenólogo, um estudo sobre o mundo social deve, na impossibilidade de analisá-lo "em si mesmo", escapar das explicações ontológicas e se limitar a descrever seus fenômenos, onde o que importa é o senso de realidade que fazemos deles (MALUFE, 1992). Goffman, 
herdeiro dessa tradição, assim faz. De acordo com Malufe (1992, p. 21), a proposta goffmaniana é que se examine a organização da experiência social, em termos de certos princípios básicos que estejam simultaneamente presentes, tanto na organização dos próprios eventos como na organização do nosso envolvimento subjetivo neles.

A escolha pelo método fenomenológico afasta, sem dúvida, a obra de Goffman da de Bourdieu. Segundo Barros Filho (2002), para este último, como o método fenomenológico não pode compreender o mundo social senão como evidente - como allant de soi -, ele "exclui a questão das condições materiais, propriamente sociais, que a tornam possível" (p. 75). Com isso, de acordo com Martins (1987, p. 3), para Bourdieu, tal modo de conhecimento não explica a coincidência entre as estruturas objetivas e as estruturas incorporadas nos agentes, o que contribui para criar a ilusão da compreensão imediata do mundo social, eliminando toda interrogação sobre as condições desta percepção natural do mundo social.

Desta forma, para Bourdieu (2002a), a análise empregada por Goffman em especial, em "Frame Analysis" (FA) - acaba tomando estruturas históricas oriundas de um mundo social e datado, por a-históricas, por quadros 4 (frames) a-temporais Em outras palavras, acaba tomando estratégias de ação e esquemas de percepção e valoração específicas a universos sociais particulares por estratégias universais, interpretando habitus específico como habitus de todos. Isto é, acaba concebendo "uma pequena parte percebida do mundo social como sua totalidade" (BOURDIEU, 1988, p.50). Para Winkin (1999, p. 75), neste ponto, "Goffman projeta na sua teoria social a sua própria ansiedade de actor em trânsito". Utilizando-se da máxima de Schopenhauer, sua "vontade e representação".

Diante disso, de acordo com ele, onde Goffman enxerga um desejo ansioso e generalizado dos agentes sociais pela apropriação de objetos de status (indicadores de valores culturais e estilos de vida) e pela defesa de uma "fachada" que os classifiquem como pertencentes a universos sociais "superiores"; Bourdieu enxerga um bluff próprio à pequena burguesia, ou seja, o princípio de sua experiência com o mundo, base mesma de sua pretensão.

Para o sociólogo francês (1988), o pequeno-burguês é quem passa a vida em busca da distinção, preocupado em possuir objetos de status e em defender uma fachada distintiva, tomando precauções para se distanciar relativamente dos seus papéis e nunca perder sua individualidade. Essas são características essencialmente dele, resultadas do seu medo de se passar por alguém pertencente às classes populares - por uma pessoa "vulgar" -, bem como do seu anseio de se passar por alguém pertencente a uma classe "superior" - de se parecer "refinado", "distinto".

Assim, para Bourdieu, enquanto a pequena burguesia encontra sua unidade na vontade de ascensão social; a burguesia tradicional se faz 
distinta justamente por não perseguir traços distintivos. Afinal, é ela quem estabelece os critérios do que é e do que não é distinto. Sua distinção, portanto, não está num suposto valor imanente de seus objetos de consumo e atividades sociais; longe disso, estes são distintos justamente porque foram apropriados por ela. Afinal, um objeto e uma atividade são classificadores sociais apenas na medida em que são classificados socialmente. Assim, a burguesia tradicional é classificada por aquilo que ela mesma classifica. Mais ainda, por aquilo que reserva a si mesma e que é sempre substituído quando difundido e, consequentemente, apropriado pelas classes subalternas. Eis a dialética da distinção. Já a pequena burguesia, ansiosa em elevar-se socialmente, passa a vida em busca de se apropriar desses objetos distintivos ${ }^{6}$, de tomar partido pela aparência,

a que deve oferecer para cumprir sua função, isto é, para desempenhar seu papel, para fazer crer e enganar, para inspirar confiança ou respeito e dar a sua personagem social, sua apresentação, sua representação, como garantia dos produtos ou serviços que propõem (é o caso dos vendedores, dos representantes comerciais, das aeromoças etc.), porém também para afirmar suas pretensões e reivindicações, para avançar seus interesses e projetos de ascensão, encontram-se propensos a uma visão berkeleyniana do mundo social, reduzida assim a um teatro no qual o ser nunca é outra coisa que um ser percebido, ou melhor, uma representação (mental) de uma representação (teatral) (BOURDIEU, 1988, p. 250).

Desta forma, podemos dizer que o recorte dramatúrgico goffmaniano universaliza hábitos de uma classe social (a que estudava). Mas não só, também confina sua análise à dimensão da cena encenada. Mais concretamente, à mesma dimensão que o observador tem dela usualmente espaços físicos concretamente limitados. Logo no prefácio da RE (2003, p. 9), Goffman esclarece que no seu entender seu trabalho serve como uma espécie de manual que descreve detalhadamente uma perspectiva sociológica a partir da qual é possível estudar a vida social principalmente aquela que é organizada dentro dos limites de um prédio ou de uma fábrica.

Por outras palavras, reduz-se a uma micro-sociologia. Em FA, sua opção pelos "quadros de referência" - "definições da situação pelas quais organizamos o conhecimento e a percepção do que acontece em nossa volta" (NUNES, 2005, p.145) - parece afastá-lo definitivamente do universo de compreensão macrossociológico, ou seja, de um enfoque analítico daquilo "que não dá visibilidade". Já a análise de Bourdieu abrese para um estudo macro-social.

Essa diferença de recorte analítico separa ambos autores em dois aspectos importantes e interdependentes: o primeiro, metodológico. Enquanto Goffman privilegia a conduta comunicativa dos agentes sociais como sua base empírica - uma conversa, por exemplo -, Bourdieu não deixa de enfatizar a importância de uma análise de cunho estatístico. O 
segundo, teórico. Enquanto para Goffman o sentido último das ações humanas deve ser retirado das interações sociais, para Bourdieu deve ser retirado à luz da história, da estrutura e da lógica de funcionamento do espaço social em que essas relações são estabelecidas.

\subsection{A crítica à competência dramatúrgica como definidora das situações cotidianas}

De acordo com Ortiz (1983, p. 20), o que Goffman "considera como determinação do agente (subjetividade), Bourdieu apreende como objetivamente estruturado". Como analisei no item anterior, o modelo dramatúrgico do primeiro compreende as interações sociais a partir de relações co-presenciais, de situações face a face. Limitando-se, portanto, a interpretar as estratégias de poder que os agentes sociais empregam na presença imediata de outros. Estratégias utilizadas fundamentalmente para dirigir e regular a impressão que possuem deles (GOFFMAN, 2003).

Desta forma, embora essas estratégias dramatúrgicas sejam muitas vezes trabalhadas em equipe - isto é, que possa existir cooperação entre os agentes sociais para o desenvolvimento de uma encenação particular (GOFFMAN, 2003) - Goffman não retira seu sentido último da estrutura e da lógica de funcionamento do universo social em que se estabelecem essas cooperações, mas, como elucida Ortiz (1983, p. 19), "dos agentes individuais que compõem o texto final". Melhor dizendo, da qualidade da encenação, objetivada nas virtudes dramatúrgicas da equipe e do desempenho ${ }^{\underline{7}}$ de cada um, que dependerão da personagem por eles representada ser acreditada ou não pelo seu público ou, melhor ainda, da cena apresentada os confirmarem ou não como legítimos no papel que reivindicam para si (GOFFMAN, 2003). Por isso, como assinala Lallement (2003b, p. 306), para Goffman, toda interação é sempre uma aposta, afinal "o indivíduo corre o risco de fazer feio realizando um gesto inconveniente, ferindo pela palavra o interlocutor".

Já na análise empregada por Bourdieu as ações humanas só podem ser compreendidas de forma adequada à luz da lógica dos espaços sociais em que são estabelecidas. Para ele, o mundo social é produto e produtor de lutas, inseparavelmente cognitivas e políticas, travadas entre seus agentes pelo conhecimento e reconhecimento de seu "ser social". Assim, embora compartilhe com Goffman que essas lutas simbólicas sejam também travadas individualmente - ou seja, que cada agente social investe na imposição da representação mais vantajosa de si, adotando estratégias múltiplas de "apresentação de si" - considera outra luta, individual ou coletiva, pelo poder de impor os princípios de construção e avaliação da representação mais legítima da realidade social. Luta que de, de um modo geral, pode se dar, segundo ele (1987), em dois planos: 
visando à transformação das categorias de percepção e apreciação do mundo social pela imposição de nomes e palavras que ajudem a construir a realidade social desejada. Ou, ainda, realizando ações destinadas a fazer existir essas realidades. A título de exemplo, uma manifestação para dar existência visual a determinado grupo social: seu número, sua força e sua coesão.

Ao fazer essa consideração e observar que as "armas" utilizadas nessas lutas sociais são desiguais e desigualmente distribuídas, ou seja, que os recursos e oportunidades de intervir no curso dos acontecimentos dessas lutas não são os mesmos para todos os agentes, Bourdieu (1988), para além de Goffman, não reduz o mundo social "à soma das representações (subjetivas) que os agentes formulam das representações (teatrais) que Ihes oferecem os outros agentes" (p.250, tradução minha). Mas, pelo contrário, o analisa fundamentalmente como uma realidade objetivamente já estruturada, isto é, marcada por assimetrias e diferenças relativamente estáveis, como diria Thompson (1995). Desta forma, segundo Ortiz (1983, p. 19), Bourdieu questiona a possibilidade de um "indivíduo definir a situação objetiva em que se dá a interação com outros parceiros".

Por essa razão, para o sociólogo francês (2003), a competência para defini-la passa necessariamente pelo volume de capital simbólico $\underline{\underline{8}}$ que cada agente possui, objetivado no quantum de autoridade que possuem nesses universos. Por outras palavras, passa pela capacidade deles de "se fazer escutar" ou, melhor, pelo direito que têm à palavra. De acordo com Bourdieu (2003, p. 149), "não falamos a qualquer um e não é qualquer um que toma a palavra. O discurso supõe um emissor legítimo destinando-se a um destinatário legítimo, reconhecido e reconhecedor". Desta forma, a competência de definir uma situação"implica o poder de impor a recepção" (BOURDIEU, 2003, p.148). Poder parcialmente já definido e hierarquizado - e não apenas produto das virtudes persuasivas de cada agente social, como quer Goffman. Por isso, segundo ele (1997, p. 71), no limite, como sugerem alguns textos de Goffman, o mundo social é o produto das ações individuais. Longe das pessoas terem condutas respeitosas porque existem hierarquias, é a infinidade de ações individuais de respeito, de deferência, etc., que termina por produzir a hierarquia.

Para Bourdieu (2005,p. 15), portanto, não se pode compreender uma interação social sem também compreender a classe social e, principalmente, o campo social onde ela é estabelecida. Nas suas palavras, "compreender é, em primeiro lugar, compreender o campo em que nos fizemos e contra o qual nos fizemos". Com isso, sua análise abre, como diria Ortiz (1983, p. 20), "a possibilidade de se estudar as relações existentes num campo determinado, as estratégias dos agentes que o compõem e o sistema de transformação ou de conservação da sociedade global". 
Desta forma, seu modelo de análise, diferentemente do da representação teatral, consegue, segundo Rabelo (1999, p. 208), “explicar o curso continuado das ações pelas quais os atores buscam o controle das suas circunstâncias práticas", e não apenas aquelas episódicas. Afinal, suas ações são interpretadas à luz dos jogos sociais que participam e aderem. Assim, ao articular estruturas objetivas e incorporadas para analisar o curso das ações, isto é, ao articular as condicionantes associadas ao espaço social onde se realiza a ação e o sistema de disposições daquele que age, Bourdieu explica o envolvimento dos agentes sociais na representação de determinadas personagens sociais (as identificadas com as de seus jogos sociais), bem como as estratégias de poder que adotam, a partir do conhecimento prático que possuem da posição social que ocupam. Melhor dizendo, de seu sentido de lugar, de seu habitus, portanto. Com isso, o sense of one's place de que fala Goffman (1986) ganha elegante compreensão sociológica na praxiologia de Bourdieu.

Finalmente, podemos dizer que Bourdieu, ao elaborar uma teoria que articula estruturas objetivas e incorporadas, consegue estabelecer um princípio organizador para explicar as práticas cotidianas dos agentes sociais e as formas como eles as percebem. Por outras palavras, oferece a eles um modo de operação coerente com suas trajetórias individuais e com a história dos espaços sociais que as forjaram, afastando-se tanto das limitações e equívocos do objetivismo como das do subjetivismo goffmaniano. Afinal, o princípio da ação, nesta forma de pensá-la, não encontra o seu impulso na consciência dos agentes, como ela aparece no modo de conhecimento subjetivista, nem na coercitividade dos fatos sociais, como a concebe o objetivismo, mas na relação entre a história objetivada, tal como aparece nas instituições sociais, e a história incorporada sob a forma de disposições duráveis (MARTINS, 1987, p. 44). Ou seja, sua praxiologia abre a possibilidade de interpretá-los na sua "concretude, como manifestação de uma totalidade", para fazer uso das palavras de Silvia Lane (1984). Com isso, vincula ontologicamente a história de cada ator com a maneira como eles interpretam as múltiplas personagens que assumem no cotidiano. Melhor, tece a história de vida de cada um deles com a história do espaço social onde suas histórias são construídas. Desta forma, Bourdieu parece conseguir amarrar os laços aparentemente soltos no esquema dramatúrgico de Goffman.

\section{Considerações Finais}

$\mathrm{Na}$ primeira parte deste trabalho, indiquei e analisei as críticas que Goffman e Bourdieu tecem à analise objetivista da ação. Na segunda, detive-me nas que o segundo dirige ao primeiro. Ao fazer isso, tentei mostrar que, embora analise, da mesma forma que Bourdieu, as relações 
humanas como relações de poder - compartilhando da idéia de que sempre ambicionamos ser "obedecidos, acreditados, respeitados e reconhecidos" (BOURDIEU, 2003, p.148) -, Goffman parece não retirar o sentido último das ações humanas da relação ontológica estabelecida entre elas e o campo social em que são realizadas. 0 que, consequentemente, afasta seu modelo de análise do de Bourdieu.

Mas se existem fissuras entre ambos os modelos, e se Bourdieu faz críticas veementes à teoria da ação de Goffman, parece também admirála profundamente. Prova disso é que, graças ao seu esforço editorial, a obra goffmaniana está mais bem traduzida em francês e mais abundantemente que a de qualquer outro sociólogo americano (WINKIN, 1999). Um belíssimo reconhecimento a este que é tratado pelos seus comentadores como o Woody Allen da sociologia americana, afinal, assim como o cineasta, dedicou-se visceralmente à vida cotidiana e à suas pequenas encenações. Certamente, 0 fato de tanto ter investido em explicações que se propunham a desmascarar as relações de poder por detrás dessas encenações tenham feito dele, assim como Bourdieu, um interlocutor reconhecido até pelos seus críticos mais ferozes - premiado no e fora de seu campo. I ronicamente, tanto um como outro, que sempre foram obstinados delatores das estratégias de obtenção de reconhecimento e status, acabaram recobertos deles.

\section{Referências Bibliográficas}

ALTHUSSER, L. I deologia e Aparelhos I deológicos do Estado. Lisboa: Ed. Presença, 1974.

BARROS FILHO, C. O habitus e o nada: um ensaio sobre as ilusões cruzadas. Revista Famecos, Porto Alegre, Porto Alegre, n. 17, p.74-88, abril/ 2002.

BONNEWITZ, P. Primeiras lições sobre a sociologia de $\mathbf{P}$. Bourdieu. Petrópolis: Ed. Vozes, 2005.

BOURDIEU, P. A Economia das Trocas Linguísticas. In: ORTIZ (Org.). A Sociologia de Pierre Bourdieu. São Paulo: Olho D`Água, 2003. p. 144169.

As regras da arte. São Paulo: Cia das Letras, 2002.

Esboço de uma auto-análise. Lisboa: Edições 70, 2005.

Esquisse d'une théorie de la pratique. Genève: Droz, 1972.

La Distincion. Madrid: Taurus, 1988.

Le sens pratique. Paris: Minuit, 1980.

Meditações Pascaliana. Rio de Janeiro: Bertrand Brasil, 1997.

O mercado linguístico. Rio de J aneiro: Ed. Marco Zero, 1983.

Raisons pratiques. Sur la théorie de l'action. Paris: Seuil, 1994. 
BOURDIEU, P.; WACQUANT, L. J. D. An Invitation to Reflexive Sociology. Chicago: The University of Chicago Press, 1992.

BURREL, G.; MORGAN, G. Paradigms and Organizational Analysis. London: Heineman, 1979.

CARMO, P. S. do. Merleau-Ponty. Uma Introdução. São Paulo: EDUC, 2004.

DURKHEIM, E. As Regras do método sociológico. In: GIANNOTTI, José Augusto. Os pensadores. São Paulo: Abril Cultural, 1978. p.71165.GOFFMAN, E. A Representação do Eu na Vida Cotidiana. Petrópolis: Vozes, 2003.

Frame Analysis: an Essay on the Organization of Experience. New York: Northeastern University Press edition, 1986.

$\overline{1} \overline{9} \overline{9} \overline{9}$.

Manicômios, Prisões e Conventos. São Paulo: Ed. Perspectiva,

LALLEMENT, M. História das I déias Sociológicas: das Origens a Max Weber. Petrópolis: Vozes, $2003 a$.

. História das Idéias Sociológicas: de Parsons aos Contemporâneos. Petrópolis: Vozes, 2003b.

LANE, S. Consciência/ alienação: a ideologia no nível individual. In: LANE, S.; CODO, W. (Orgs.). Psicologia Social: o homem em movimento. São Paulo: Brasiliense, 1984.

MALUFE, J. R. A Retórica da Ciência: uma leitura de Goffman. São Paulo: EDUC, 1992.

MARTINS, C. B. Estrutura e Ator: A Teoria da Prática em Bourdieu. Revista Educação \& Sociedade, São Paulo, vol. 9, n. 27, p. 33-46, setembro 1987.

NUNES, J. H. I nteracionismo simbólico e dramaturgia. A sociologia de Goffman. São Paulo: Ed. Humanitas, 2005.

ORTIZ, R. A procura de uma sociologia da prática. In: Pierre

Bourdieu: sociologia. São Paulo: Ática, 1983. p. 8-36.

RABELO, M. A Experiência de Indivíduos com Problema Mental: entendendo projetos e sua realização. In: RABELO, M. C.; ALVES, P. C.; SOUZA, I. M. (Orgs.). Experiência de Doença e Narrativa. Rio de Janeiro: Ed. FioCruz, 1999. p. 205-227.

THOMPSON, J. B. I deologia e cultura moderna: teoria social crítica na era dos meios de comunicação de massa. Petrópolis: Vozes, 1995.

WINKIN, Y. . The French (Re)presentation of Goffman's Presentation and Other Books. Theory Culture and Society, London, vol. 2, n. 1, p. 109-113, 1983.

Erving Goffman: Retrato do sociólogo enquanto jovem. In: GOFFMAN, Erwin. Os Momentos e os Seus Homens. Lisboa: Relógio D’Água, 1999. p. 11-96.

Endereço para correspondência 
Felipe Tavares Paes Lopes

Instituto de Psicologia da Universidade de São Paulo, Av. Prof. Mello Moraes, 1721, Bloco

A, Cidade Universitária, CEP: 05508-030, São Paulo, SP, Brasil.

Endereço eletrônico: ftplopes@yahoo.com.br

Recebido em: 20/05/2008

Aceito para publicação em: 04/12/2008

Editor responsável: Anna Paula Uziel

\begin{abstract}
Notas
-Bolsista CNPq.

1 Expressão utilizada por Goffman (2003) para se referir "a toda atividade de um indivíduo que se passa num período caracterizado pela sua presença contínua diante de um grupo de um grupo particular de observadores e que tem sobre estes alguma influência" (p.29).

2 Sua ruptura com a abordagem fenomenológica de Merlau Ponty consiste justamente em rejeitar a noção de um habitus fundado por um projeto e uma situação que se fundem. Sobre o assunto, ver RABELO, 1999.

3 Embora Winkin (1988) observe que Goffman tenha tomado uma posição parsoniana na sua tese doutoral, e que nunca mais a tenha deixado - observando que "entre a noção de sistema e a de ordem social, há, tanto em Parsons como em Goffman, uma espécie de consaguinidade" (p.64-66) - é possível afirmar que Goffman se contrapõe a Parsons em dois aspectos: o primeiro, apontado pelo próprio Winkin, diz respeito às interações sociais. Se para Parsons elas são compreendidas como mecanismos de regulação da ordem social, ainda que sempre frágeis e nunca totalmente garantidos; para Goffman, são compreendidas "não como cena de harmonia, mas como disposição que permite prosseguir uma guerra fria" (GOFFMAN apud WINKIN, 1988, p.65). O segundo diz respeito à questão do desvio. Se para Parsons ele é o resultado de uma desordem no ambiente social, de suas regras e valores; para Goffman, é sempre uma construção social. Mais concretamente, uma atribuição que visa à dominação daquele que a estabelece. Esta tese é desenvolvida por ele fundamentalmente em "Estigma" (1980) e "Manicômios, Prisões e Conventos" (1999a).

4 Definido por Goffman (1986) como "princípios de organização que governam os eventos sociais e nosso envolvimento subjetivo neles" (p.10-11).

5 Definida por Goffman (2003) como "à parte do desempenho do indivíduo que funciona regularmente de forma geral e fixa com o fim de definir a situação para os que observam a representação. Fachada, portanto, é o equipamento expressivo de tipo padronizado intencional ou inconscientemente empregado pelo indivíduo durante a representação" (p.29).

6 Embora a simples posse desses objetos não Ihes confiram grande status. Para tanto, é preciso consumi-los de forma legítima - da forma como a burguesia tradicional os consome. É preciso mostrar familiaridade com esses bens.

${ }^{7}$ Definido por Goffman (2003) "como toda atividade de um determinado participante, em dada ocasião, que sirva para influenciar, de algum modo, qualquer um dos outros participantes" (p.23).

8 Corresponde ao acúmulo de rituais ligados à honra e ao reconhecimento pelos quais um agente social passa. Confere a ele crédito e autoridade, que podem ser convertidos nas outras três formas de capital existentes: o econômico, o cultural e o social. Sobre o assunto, ver BOURDIEU, 1988.
\end{abstract}

